David L. Boose, GONZAGA UNIVERSITY, boose@gonzaga.edu

Pat Hutchings, GONZAGA UNIVERSITY, hutchings.pat@gmail.com

\title{
The Scholarship of Teaching and Learning as a Subversive Activity
}

\begin{abstract}
One of the most serious challenges facing higher education today is the erosion of academic culture-a declining sense that faculty form a community whose members reflect, deliberate, and make decisions together in the name of a shared educational vision. Our experience with Gonzaga University's Scholarship of Teaching and Learning (SoTL) Initiative suggests that SoTL can be a powerful counter force to this erosion. What became increasingly evident as the initiative unfolded was that its most important result was the creation of a kind of alternative academic community that stands in opposition to many of the dis-integrative, disempowering forces at work in higher education. The scholarly examination of practice, done in a collaborative context, changed participants' perceptions of learning, of themselves as teachers, and of the larger endeavor of which they are a part. Thus, we came to see the SoTL initiative as a subversive activity in the sense used by Neil Postman and Charles Weingartner in their 1969 book, Teaching as a Subversive Activity. one that invites critical questions about education's purposes, practices, and underlying assumptions, and in so doing reanimates core values.
\end{abstract}

\section{KEYWORDS}

SoTL, faculty learning community, higher education, inquiry

The stresses and strains on higher education today are well known. In a period of economic instability and budget cutting, colleges and universities around the world are being asked to do more with less. The "completion agenda," as it's called in the US, puts a premium on retention and graduation rates, with policies and metrics that can seem to be more about moving students through the system than about what happens to them within it. Campus administrators, faced with rising costs and real limits on the ability to increase tuition, must turn their attention to credit-hour generation and efficiency. Calls for accountability - quality assurance and improvement schemes in the UK (Clark, 2009), Canada (Council of Ministers of Education, Canada, 2007; Nicholsen, 2011) and Australia (Baird, 2011), for instance, and the assessment movement in the US (Ewell, 2009) —ask, appropriately, for evidence of student learning. But these programs sometimes do more to increase the level of bureaucracy than to improve the educational experience of students (Banta \& Blaich, 2011; Newton, 2000). And a variety of "disruptions"-including MOOCs, certificate programs offered by industry, and other online offerings that compete with traditional curricula-raise serious questions about the role of faculty in designing the learning experience and overseeing its quality.

These developments reflect real issues and challenges facing higher education; they cannot simply be dismissed as misunderstandings on the part of those outside the system. And some of them can, admittedly, be forces for positive change. But for many academics, they also point to a loss - a sense 
that decisions about the fundamental purposes and processes of the educational enterprise are moving further from our grasp. This trend, documented over several decades (Macfarlane, 2005; Massey, Wilger, \& Colbeck, 1994; Rhoades, 1998; Rice, 2006), reflects an erosion of academic culture — the opportunity to be part of a community whose members reflect, deliberate, and make decisions together in the name of a shared vision. Thus, among the many other challenges now facing higher education is this additional and fundamental one: how to revitalize among faculty a sense of common academic purpose and meaning.

Here, we explore this challenge through the lens of a Scholarship of Teaching and Learning (SoTL) initiative at Gonzaga University (GU), which we planned, facilitated, and documented during the 2012-2013 academic year. Like many institutions, Gonzaga turned to SoTL with multiple goals in mind: to be part of an international movement to recognize the intellectual work of teaching, to understand more about the students we work with and how they learn, to offer opportunities for meaningful scholarship to faculty whose primary interests lie in teaching, and to support other institutional improvement agendas such as curricular reform or assessment (Ciccone, 2008; Huber \& Hutchings, 2005; Hutchings et al., 2013; Roxa, Olsson, \& Martensson, 2008). But what became increasingly evident as the initiative unfolded is that its most important result was the creation of a kind of counterculture for the participants, an alternative academic community that stands in opposition to many of the dis-integrative, dis-empowering forces at work in higher education as they were being experienced by GU faculty. Thus, although we did not recognize it as such at the outset, we came to see the SoTL initiative as a subversive activity in the sense used by Neil Postman and Charles Weingartner in their 1969 book, Teaching as a Subversive Activity (the title of which we have unabashedly repurposed) —one that invites critical questions about education's purposes, practices, and underlying assumptions, and in so doing reanimates core values.

This aspect of the Scholarship of Teaching and Learning has been noted by others, certainly. Carolin Kreber (2013) has been a persistent advocate for a broad vision of SoTL, one where "endeavours aimed at improving learning and creating a better world within which to learn and teach are nested within the larger concern for creating a better world' (p. 13; emphasis in original). Similarly, Tai Peseta, Angela Brew, Kim McShane, and Simon Barrie (2007) noted that the Scholarship of Teaching and Learning is "about infusing pedagogical work with a new spirit; perhaps even a moral spirit .... It is a movement that asks: what is the university for and how is teaching and learning to enact that purpose?" (p. 223) And the power-shifting idea that students should be real partners in such work, and should participate in shaping teaching and learning experiences, has become a vital force within the Scholarship of Teaching and Learning community (see, for instance Cook-Sather, Bovill, \& Felten, 2014; Healey, 2012; Werder \& Otis, 2010). In short, the Scholarship of Teaching and Learning is work that invites critical thinking about basic assumptions and purposes, and about the way we do our work as educators. And that can be subversive.

What we saw at Gonzaga was how the subversive potential within the Scholarship of Teaching and Learning was heightened and enhanced through the use of a faculty learning community-a model that brings people together to engage in inquiry. Working as a group to investigate their students' learning, participants discovered intersecting problems and interests and developed shared language, trust, and common ground. They talked about how the experience made a difference to them as individuals, but also how they increasingly saw the group as a kind of alternative community to which they did not have access in the daily routines of their academic lives. Collaborating across disciplinary lines and status distinctions made it possible to slow down, reflect, make connections, and rediscover common cause. 
This evolving sense of community (it took time to emerge) led, in turn, to a richer vision of learning and teaching. Working together as trusted colleagues, participants were able to ask hard questions about their own thinking and practice as teachers-questions that sometimes led, or risked leading, to uncomfortable conclusions: we work long hours as academics to design experiences that will be transformative for students, but are students really changed? Are we, as a group, sending students consistent, clear signals about what it means to be an educated person? How much do we really know about our students as learners? And although no one used the word "subversive," it was clear over time that the group's collective deliberations, the questions they asked and the honesty of their answers, exposed a richer view of learning — an alternative to what Joëlle Fanghanel (2013) described as today's "de-contextualized and dis-intellectualized views of teaching" (p. 60). In this sense, we argue, the Scholarship of Teaching and Learning, undertaken in a faculty learning community, can push back against the overly simple production models of education that tend to dominate public discourse today, raising up a more generative vision.

Our aim in this paper is to reflect on the Gonzaga initiative as an example of the Scholarship of Teaching and Learning as a subversive activity-one that counters feelings of faculty isolation and powerlessness, and opens up a space for critical questions about one's own work as a teacher and the purposes of education. Following a brief overview of the institution and the initiative, we examine the emergence of two themes noted above: the building of a professional teaching community, and the development, as a consequence, of a "complexified"-i.e., more nuanced and context-specific — vision of learning. Though our aim is not to provide a blueprint for a Gonzaga-like program, we also explore some of the key elements that shaped the experience of the group and fostered these outcomes. Our hope is to contribute to the work of those (like us) who provide direct support for the Scholarship of Teaching and Learning on campuses, but to speak, as well, to a broader audience of scholars and leaders interested in the meaning, purpose, and rationale for such work in today's educational context. As Patricia O'Connell Killen and Eugene Gallagher (2013) observed, "No discussion of the scholarship of teaching is neutral" (p. 107). We agree, and our purpose here is to contribute to a line of thinking that frames SoTL not only as an emergent or additional arena for faculty work, but also as a force for deeper change.

\section{INSTITUTIONAL CONTEXT}

Located in the Pacific Northwest of the USA, Gonzaga University (GU) is a private, residential Jesuit institution serving approximately 5000 undergraduates and 2400 graduate students across six schools. Prior to 2012, the university had almost no history of attention to or awareness of SoTL, despite an emphasis on excellent teaching as a key part of its identity. But other institutional characteristics created fertile ground for introducing the faculty to such work. In response to pressure from accrediting agencies, the university had been placing increased emphasis on defining learning outcomes and assessing programs. A new president and a new academic vice president (AVP) had joined the institution three years previously, and the AVP in particular brought experience and interest in SoTL. Additionally, a five-year project to examine and redesign the university's core curriculum had resulted in a set of Baccalaureate Goals-learning outcomes for the entire undergraduate experience-and outcomes-based proposals for new core curriculum models. As a consequence, the university had been developing new vocabulary and perspectives that framed teaching in a more intentional way and generated an appetite for evidence about learning.

The university's Jesuit mission and tradition also gave it some older vocabulary for introducing the idea of a scholarly approach to teaching. The Ignatian pedagogical approach (named after St. Ignatius of Loyola, the founder of the Jesuits) centers around five key components: context, experience, 
reflection, action, and evaluation (Korth, 2008). Many faculty had at least heard of these concepts as central tenets of Jesuit pedagogy and saw them as a ready framework within which to ask questions about students and classes: what do Gonzaga students bring to my class? What experiences do they have there? How do I help them to reflect on those experiences? What do they do as a result? How does that compare with what I want them to get from the class? Thus, the kind of inquiry into one's own teaching that lies at the heart of SoTL can be seen as a natural expression of the university's mission and tradition.

The final important aspect of institutional context is GU's Center for Teaching and Advising (CTA), the university's faculty development office. Founded in 2006 as the result of a faculty-driven initiative, the Center has a reputation for high-quality programs that are useful to faculty, including several year-long, cohort-based initiatives. With strong financial support from the AVP, the Center thus provides both an administrative structure and a level of credibility among faculty that made it the appropriate host for GU's first systematic foray into SoTL.

\section{THE GU SCHOLARSHIP OF TEACHING AND LEARNING INITIATIVE}

The Scholarship of Teaching and Learning initiative began in February 2012 with a call for proposals open to faculty at all levels and in all fields and disciplines. Applicants were asked to identify a question about student learning in a course that they would be teaching during the following academic year, explain why the question was important, and describe the kinds of evidence needed in order to answer the question. We recognized that most applicants would have little formal experience in SoTL, so we also asked them to identify any concerns or questions they had about the project, and the kinds of support and assistance that would be most important to them in carrying it out. A panel of six faculty with some experience in SoTL or related research (including the authors) reviewed the proposals, and in the end accepted all twelve that were received - though several applicants were asked to revise for clarity or focus and then resubmit.

As hoped, the proposed projects were wide-ranging, representing communication studies, English, human physiology, organizational leadership, philosophy, political science, psychology, and religious studies. Several participants were looking at students' evolving practices as readers, writers, and citizens; several were exploring how students assess their own learning; one was interested in issues of cognitive load related to student note-taking behaviors; and a team from organizational leadership was focused on the dynamics of adult learners in an online environment.

The initiative was structured as a faculty learning community (Cox, 2004; Richlin \& Cox, 2004), as an established and effective model for facilitating collaborative inquiry and one that the CTA employs in other programs. Specifically, the group met for a two-day intensive workshop in May, followed by regular meetings throughout the following academic year, at about three-week intervals. We, the authors of this article, facilitated the meetings, providing direction where needed and making occasional "assignments" (for example, to read and report on the scholarly literature relevant to their question, and to draft the opening section of a possible essay about their findings). But, in the spirit of a faculty learning community, we typically let the needs and issues facing participants drive the conversation.

Because we wanted to emphasize the scholarly nature of this work, we also offered a two-day writing retreat in July of 2013. While eventual publication would be a valuable outcome, we encouraged the writing process primarily as a stimulus to further reflection, exchange, and meaning making. In this spirit, the retreat provided time for participants to consult with one another about the insights and wider lessons from their work, as well as giving them time and space to write. (Since that time, several members of the group have submitted essays for publication or made professional presentations about their work.) 
This structure, with individual faculty pursuing scholarly inquiry into the experiences that occur in their classrooms, but in a structured, collaborative, and supportive cohort, created the conditions for the emergent sense of an alternative community identity we observed from the SoTL initiative.

\section{CREATING A COMMUNITY OF CONVERSATION}

Teaching would seem to be a highly social activity. But, as former Carnegie Foundation president Lee S. Shulman (1993) pointed out twenty years ago in a widely quoted essay, the reality for many faculty is more accurately characterized as "pedagogical solitude," (p. 6) with the classroom door both literally and metaphorically closed. That reality has arguably begun to shift as new practices, tools, and occasions for sharing the intellectual work of teaching have been developed and spread (Bernstein, Burnett, Goodburn, \& Savory, 2006; Hatch, Bass, liyoshi, \& Pointer Mace, 2004; Hutchings, 1996), but the Scholarship of Teaching and Learning's mantra of "making teaching public" remains an unfinished agenda.

In many settings the idea of sharing work on teaching is simply not yet a habit. While it may not be actively resisted, neither is it something academics are comfortable with or actively seek out. In part this may be due to the fact that careful examination of one's teaching can be risky. For example, we may risk discovering that the course we love to teach, and have carefully designed over many semesters, is not leading to the outcomes that matter most for students. Or we may find that the course we teach with such pride strikes our colleagues as outdated or missing the mark. As one of the participants in our initiative put it, "there are few occasions to talk to each other in low-stakes settings about teaching."

And there are counterforces at work. Many campuses where teaching was once emphasized over other activities now expect faculty to engage in traditional, discipline-based scholarship (Glassick, Huber, \& Maeroff, 1997; O’Meara \& Rice, 2005). Fund raising, recruiting, and committee work make added demands on faculty time. And requirements for assessment, quality assurance, accreditation, and program review constitute significant additions to the list of things-that-must-be-done. Since most of these demands come from outside the faculty-from administrators, accreditors, legislatures, boards of trustees, campus development offices, and the like-faculty may feel they have less of a voice in determining the priorities of the institution and are increasingly called on simply to "do the work." What was once a collegial culture where critical issues were worked out through ongoing exchange and deliberation among peers, has been replaced, argued sociologist Gary Rhoades (1998), by a managerial one. Fanghanel (2013) points out that the data-based decision-making that does occur on campuses tends to be focused on institutional outputs, competitiveness, and funding — what she called "'managed' research" (p. 60) - in contrast with scholarship focusing on teaching and learning. In short, there is precious little time or encouragement for collegiality and collaboration around the work of teaching that many faculty care deeply about.

Clearly, the dynamics of this reality play out differently, and to different degrees, on different campuses. At Gonzaga, interviews with chairs from units represented in the Scholarship of Teaching and Learning initiative revealed that organized time and space for discussion about teaching was often hard to come by. One chair noted, for instance, that in spite of his commitment to improving teaching, issues of pedagogy were often pushed off the department meeting agenda by more "urgent items," such as retention or marketing. And conversations with a larger group of GU chairs in the fall of 2011 uncovered a shared sense that the institution had moved from a collaborative culture where people work together across various contexts and borders to one that is much more formalized and bureaucratic, and where opportunities for collegial interaction are rare (Hutchings, 2011). 
It is in this context that collaborative work on the Scholarship of Teaching and Learning becomes countercultural. Participants in the SoTL initiative underlined this sense. One argued that the institution would benefit from more "open opportunities for people to think in this way about what we do-more intentionally." And nearly all of them told us in an end-of-program reflective writing activity that "the most useful" aspect of the experience was the opportunity to be part of a group that worked together on the challenging issues of teaching and learning. We had expected some of this response because faculty learning communities are known to foster collegial relations (Cox, 2004). But the strength and pervasiveness of it surprised us, and made us want to understand more about the experience of program participants.

Toward this end, we subsequently analyzed records of group discussions, the end-of-program reflective writing exercise mentioned above, and written comments on a final evaluation. We found that participants had experienced shifts in their perceptions of teaching, teachers, and themselves as faculty members. "It made me see teaching as something to be talked about regularly with my peers outside of my department, as a complete and worthwhile endeavor," one person wrote. "It helped me to see these colleagues for the committed, creative and caring professionals they truly are and to see myself as that kind of professional by extension." Another noted that the experience made him appreciate his colleagues in a new way. At one level, these comments reflect the satisfaction that comes from finding valued new colleagues - a goal that many scholars of teaching and learning report, and a commonly reported outcome of participation in such programs (see Cox, Huber, \& Hutchings, 2005; Voelker \& Martin, 2013). But we believe it's more than this — that seeing "myself as that kind of professional" and appreciating one's colleagues "in a new way" is part of an identity-building process.

The subversive impact of the Scholarship of Teaching and Learning on academic identity is generally viewed in terms of individual development (Huber, 2004; Sommers, 2004; Voelker \& Martin, 2013), and often stresses the negotiation of conflicts experienced when moving into what can be "troubling" work (Simmons et al., 2013). Gonzaga participants spoke about such challenges and development as well. But what was striking to us was the sense of shared transformation, of belonging to something larger. One wrote,

Participation in the SoTL Initiative has the capacity to build community within the faculty that crosses disciplinary and departmental boundaries by helping us to understand and appreciate each other and our common ground as human beings, teachers, and scholars; and to support each other in doing what we do more effectively.

Another noted, "The SoTL [initiative] helps us to become a more holistic faculty, not only continuing to grow in our own subject matter but engaging one another appreciably across the disciplines to understand how to teach and help students learn what it means to be a person educated in the values prioritized by Gonzaga University." In comments like these, we see the community-building aspect of SoTL not simply as the good-but-fleeting feeling of colleagueship but as an experience of continuing, shared growth and development. That experience occurs (in the words of initiative participants) on "common ground," in which faculty are "engaging one another appreciably" around questions of educational purpose, meaning, and values. The result is the development of a more collective identitya vision of teaching as a professional community that stands in opposition to the day-by-day, often isolating realities of academic life today.

To be clear, we are not saying that everyone in the group was deeply engaged at every moment, or that the sense of community that emerged was not fragile. But in our view, the experience of these 
twelve participants provides a window into the potential of the Scholarship of Teaching and Learning to be transformative not only at the individual level, but also collectively. Changing an individual participant's view of him- or herself also changes that person's view of his or her colleagues and the endeavor in which they are all engaged. In this way, SoTL can plant the seeds for broader cultural transformation, and it is useful for institutions to have this potential in mind as they organize for this kind of work. Done collaboratively, SoTL becomes more than a means to an end, or an instrumental activity probing questions of educational effectiveness. It can change the way people think about themselves, their membership in a professional community, their practices as teachers, and (our next topic) their very conception of learning.

\section{"COMPLEXIFYING" THE CONCEPTION OF LEARNING}

It might seem obvious that academics would put significant energy and time into exploring and understanding their students' learning, but as with the formation of collegial communities, many forces today work against that goal. In spite of what is known about the learning process, higher education policy today is driven in large part by a too-simple production model of education that emphasizes access, credit-hour generation, progress toward a degree, graduation rates, and costs (Obama, 2013; Weingarten, 2013). The value attributed to any particular field of study emphasizes the potential for employment after graduation over the actual learning that takes place in college (see Schneider, 2013, for an account of and response to this trend). And among our participants, there was deep concern about how these views are reflected in student attitudes toward learning. The group's discussion returned repeatedly to concerns about students who simply want "the right answer." One participant noted that "students have been programmed to get facts and answers; they don't ask themselves questions."

It is against this backdrop that SoTL can deepen its subversive role. Faculty engaged in such inquiry provide a counter narrative, seeing and going public with the complexity that characterizes powerful student learning. To borrow from the lexicon of Ignatian pedagogy, SoTL invites and requires contemplation, which Jesuit theologian Walter Burghardt (1989) described as "a long, loving look at the real" (p. 14). The Scholarship of Teaching and Learning asks for a kind of care and attention that requires time. This careful reflection on the specific question being asked and the specific evidence being gathered emphasizes the complex, nuanced, and highly contextual nature of learning. One of our participants described this as "re-personalizing learning" - bringing the focus back to individual students, their diverse backgrounds, and the unique processes through which each will make meaning of the experiences presented by our classes. This is a vision in stark contrast to the production model.

The experiences of two participants in our project help to illustrate this re-personalization. Heather Easterling, a faculty member in English, proposed to investigate reading. As she stated in her initial proposal, she wanted to know "what [students] think it means to 'read' and what they do when they read a written text, especially a literary text.” Her project centered around a literature course typically taken by first- or second-year students that has as one of its goals to help students become more active and critical readers. Easterling wanted to "more attentively investigate where they are starting from as readers as well as what kinds of assignments and activities most encourage and develop active, critical (college-level) reading." Christina Geithner, a professor of human physiology, was interested in another fundamental academic skill: writing. Specifically, Geithner's proposal addressed her desire to develop students' abilities to "think like scientists in order to be able to write like scientists." Her project was to redesign a sophomore-level course for majors and explore active, inquiry-based approaches that could be used to improve students' writing skills. 
Both of these faculty members are accomplished readers and writers themselves, and have years of experience teaching classes to develop these skills in students. Yet both found that the process of systematic, sustained inquiry into what and how students were learning challenged their perspectives. They realized that what they wanted was not only for students to be able to read or write, but to see themselves as readers, as writers. That is, the learning they desired was as much about identity formation and self-assessment as about skill development. Indeed, this was a common discovery among most of the participants in the initiative. Nearly everyone spoke of wanting students to "see themselves as" something-a writer, a citizen, a thinker. And they wanted the process of becoming that "something" to be more visible, so students could monitor, direct, and assess their own development and become more active partners in their educational experience.

The realization that learning is about becoming rather than mastering also focused participants' attention on their own process as learners. As experts, faculty have generally acquired their skills and approaches to learning over long periods of acculturation within their discipline's community of practice (Brown, Collins, \& Duguid, 1989; Wenger, 1998). As a result, they are so familiar with the steps they use to gather and process information, those steps are largely invisible to them (see for instance Roth \& McGinn, 1997, on making and using graphs; or Wineburg, 2001, on how historians read primary sources), and it can be difficult for them to recall what it is like to be a novice learner (see Hinds, 1999, on "the curse of expertise," and Middendorf \& Pace, 2004, on the usefulness of "decoding the disciplines"). But a close examination of students' learning can help to make that process more visible. As one of our participants put it, looking at the evidence from projects presented and discussed during one of our sessions, "There is nothing automatic about reading, thinking, and talking. They are learned skills which require a broad knowledge base and different ways of knowing and reasoning." This realization fostered greater intentionality among the participants toward helping students see the processes they are going through as they learn.

But making the learning process visible requires slowing down. Easterling, the English professor, reflected, "I am more aware than ever that we must devote class time to practicing and discussing the moves of active, critical readers. And this is a kind of attention that is relevant and appropriate at every level of college-reading, even while it is especially critical for entering students." This imperative to make things visible, to provide multiple opportunities for practice - to slow down-runs counter to the prevailing pressures both at the institutional and larger societal levels that push to move students through the system as quickly as possible. In short, SoTL's "long, loving look" at teaching and learning in the classroom prompted a greater appreciation for-and commitment to-the complexity of learning and the processes that foster it, in direct contrast to the production model that underlies so much institutional practice and educational policy today.

\section{A NEW SPIRIT}

When Postman and Weingartner (1969) described teaching as "a subversive activity," their context was the rapidly changing social, economic, and political environment of the 1960s. They identified three particular phenomena driving the need for a new perspective on education: dramatic changes in the nature of communication, an ever-increasing rate of social and technological change, and the "burgeoning bureaucracies" that tend to impede, rather than promote, the development of strategies to address the first two phenomena. Postman and Weingartner's argument was that education should develop in students an "anthropological perspective" - the ability to both be part of a culture and also be critically aware of it - not necessarily to oppose the changes that are occurring, but to identify, critique, and respond appropriately to them. Without this perspective, they argue, the most likely responses are to 
withdraw with a sense of impotence, or to continue blindly as one has, in denial of the change that is occurring.

We are making a more specific argument than Postman and Weingartner, focused on the conditions of teaching and learning in higher education today as reflected in our experience with faculty participants in Gonzaga's Scholarship of Teaching and Learning initiative. But that experience clearly has parallels with the dynamics they report. Undertaken in the context of a learning community, SoTL can be a powerful countercultural force helping faculty identify, critique, and respond to the rapid changes facing higher education today. Dramatic changes in communications, educational technology, and perceptions of the value and purpose of higher education have eroded faculty members' sense of common purpose and meaning, as well as their feelings of agency and control over the educational process (Macfarlane, 2005; Massey et al., 1994; Rhoades, 1998; Rice, 2006). Up against those losses, the collaborative, scholarly examination of teaching and learning fostered among GU faculty the anthropological perspective that Postman and Weingartner advocate. Participants were simultaneously members of the culture and critical examiners of it, and this changed their perceptions of both themselves and the larger endeavor of which they are a part. The process required the development of a common vocabulary and the recognition of shared goals and values, and fostered a more complex, nuanced, and critical understanding of what it means to teach and to learn.

As we mentioned above, a number of factors made Gonzaga University ready to initiate a SoTL learning community. Other institutions will have different conditions and perhaps more challenging contexts in which to undertake these kinds of programs. Almost all campuses today are facing tight budgets, and administrators are understandably asking questions about the return on their investment in various initiatives, including the Scholarship of Teaching and Learning (Hutchings, Huber, \& Ciccone, 2011). Does it improve retention? Create more student learning? Those are fair and important questions.

But we are arguing for a different framing of the power and meaning of this work, which we saw emerge from the conversations and experiences of our faculty participants: that a learning community dedicated to the Scholarship of Teaching and Learning may indeed lead to tangible gains in learning and retention (and of course those matter greatly), but that its more distinctive contribution lies in its ability to foster a sense of identity and perspective among educators that allows both a critical evaluation of, and a richer participation in, the work of higher learning.

Toward the end of the initiative, we invited the academic vice president to join the SoTL program's participants for a conversation about the meaning of their work-for them and for the institution. Mostly, she listened, and what she heard was about a process of inquiry and community building that led to greater intentionality in the classroom, more sense of connection to the work of colleagues and to the institution, keener insights into the learning of Gonzaga students, and a different sense among participants of themselves as professionals. Her comment at the conclusion of the discussion seemed to capture the experience around the table: "The way this was constructed, it's a moment in time when your jobs as teachers, scholars, and members of a community are undivided. You don't feel cleaved." Done communally, the Scholarship of Teaching and Learning is not just a project, but an ethos, a set of principles and commitments that can revitalize a sense of common academic purpose and meaning, and it is in that sense that it can be a valuable, and subversive, activity.

\section{David Boose is Professor of Biology at Gonzaga University in Spokane, Washington (USA). From 2007-2015 he served as the Director of Gonzaga University's Center for Teaching and Advising.}


Pat Hutchings was the Scholar in Residence at Gonzaga University's Center for Teaching and Advising from 2012-2015. She is a former vice president of the Carnegie Foundation for the Advancement of Teaching (USA).

\section{REFERENCES}

Baird, J. (2011). Accountability in Australia. In B. Stensaker \& L. Harvey (Eds.), Accountability in higher education: Global perspectives on trust and power (pp. 25-48). New York, NY: Routledge.

Banta, T.W., \& Blaich, C. (2011). Closing the assessment loop. Change: The Magazine of Higher Learning, 43(1), 2227.

Bernstein, D., Burnett, A. N., Goodburn, A., \& Savory, P. (2006). Making teaching and learning visible: Course portfolios and the peer review of teaching. San Francisco, CA: Jossey-Bass.

Brown, J. S., Collins, A., \& Duguid, P. (1989). Situated cognition and the culture of learning. Educational Researcher, 18(1), 32-42.

Burghardt, W. (1989). Contemplation: A long loving look at the real. Church, 5, 14-18.

Ciccone, T. (2008). Examining the impact of SoTL. International Commons, 3(1), 12-13. Retrieved from http://www.issotl.org/international_Commons_3.1.pdf.

Clark, T. (2009). Impact of reforms on the quality and responsiveness of universities in the United Kingdom. Higher Education Management and Policy, 21(2), 107-122.

Cook-Sather, A., Bovill, C, \& Felten, P. (2014). Engaging students as partners in learning and teaching: A guide for faculty. San Francisco, CA: Jossey-Bass.

Council of Ministers of Education, Canada (2007). Ministerial statement on quality assurance of degree education in Canada. Retrieved from http://www.cmec.ca/Publications/Lists/Publications/Attachments/95/QAStatement-2007.en.pdf.

Cox, M. D. (2004). Introduction to faculty learning communities. New Directions for Teaching and Learning, 97, 523.

Cox, R., Huber, M. T., \& Hutchings, P. (2005). Survey of CASTL Scholars. In M. T. Huber \& P. Hutchings (Eds.), The advancement of learning: Building the teaching commons (pp. 133-150). Stanford, CA: Carnegie Foundation for the Advancement of Teaching.

Ewell, P. (2009). Assessment, accountability, and improvement: Revisiting the tension. (NILOA Occasional Paper No. 1). Urbana, IL: National Institute for Learning Outcomes Assessment.

Fanghanel, J. (2013). Going public with pedagogical inquiries: SoTL as a methodology for faculty professional development. Teaching \& Learning Inquiry, 1(1), 59-70.

Glassick, C. E., Huber, M. T., \& Maeroff, G. I. (1997). Scholarship assessed: Evaluation of the professoriate. San Francisco, CA: Jossey-Bass.

Hatch, T., Bass, R., liyoshi, T., \& Pointer Mace, D. (2004). Building knowledge for teaching and learning: The promise of scholarship in a networked environment. Change: The Magazine of Higher Learning, 36(5), 42-49.

Healey, M. (2012). Students as change agents. Retrieved from http://www.mickhealey.co.uk/resources.

Hinds, P. J. (1999). The curse of expertise: The effects of expertise and debiasing methods on prediction of novice performance. Journal of Experimental Psychology: Applied. 5(2), 205-221.

Huber, M. T. (2004). Balancing acts: The Scholarship of Teaching and Learning in academic careers. Washington, DC: American Association for Higher Education.

Huber, M. T., \& Hutchings, P. (2005). The advancement of learning: Building the teaching commons. San Francisco, CA: Jossey-Bass.

Hutchings, P. (Ed.). (1996). Making teaching community property: A menu for peer collaboration and peer review. Washington, DC: American Association for Higher Education.

Hutchings, P. (2011). Report to the AVP on interviews with Gonzaga University chairs. Unpublished report.

Hutchings, P., Borin, P., Keesing-Styles, L., Martin, L., Michael, R., Scharff, L., Simkins, S., \& Ismail, A. (2013). The Scholarship of Teaching and Learning in an age of accountability: Building bridges. Teaching \& Learning Inquiry, 1(2), 35-47.

Hutchings, P., Huber, M. T., \& Ciccone, A. (2011). The Scholarship of Teaching and Learning reconsidered: Institutional integration and impact. San Francisco, CA: Jossey-Bass.

Killen, P. O., \& Gallagher, E. V. (2013). Sketching the contours of the Scholarship of Teaching and Learning in theology and religion. Teaching Theology and Religion, 16(2), 107-124. 
Korth, S. J. (2008). Précis of Ignatian pedagogy: A practical approach. In G. W. Traub, (Ed.), A Jesuit education reader (pp. 280-284). Chicago, IL: Loyola Press.

Kreber, C. (2013). The transformative potential of the Scholarship of Teaching and Learning. Teaching \& Learning Inquiry, 1(1), 5-18.

Macfarlane, B. (2005). The disengaged academic: The retreat from citizenship. Higher Education Quarterly, 59(4), 296-312.

Massey, W., Wilger, A., \& Colbeck, C. (1994). Department cultures and teaching quality: Overcoming "hollowed" collegiality. Change: The Magazine of Higher Learning, 26(4), 11-20.

Middendorf, J., \& Pace, D. (2004). Decoding the disciplines: Helping students learn disciplinary ways of thinking. New Directions for Teaching and Learning, 98, 1-12.

Newton, J. (2000). Feeding the beast or improving quality? Academics' perceptions of quality assurance and quality monitoring. Quality in Higher Education, 6(2), 152-163.

Nicholsen, K. (2011). Quality assurance in higher education: A review of the literature. Retrieved from http://cll.mcmaster.ca/COU/pdf/Quality\%20Assurance\%20Literature\%20Review.pdf.

Obama, B. H. (2013). Remarks by the President on college affordability -- Buffalo, NY (August 22, 2013). Retrieved from https://www.whitehouse.gov/the-press-office/2013/08/22/remarks-president-collegeaffordability-buffalo-ny.

O'Meara, K., \& Rice, R. E. (Eds.). (2005). Faculty priorities reconsidered: Rewarding multiple forms of scholarship. San Francisco, CA: Jossey-Bass.

Peseta, T., Brew, A., McShane, K., \& Barrie, S. (2007). Encouraging the scholarship of learning and teaching in an institutional culture. In A. Brew \& J. Sachs (Eds.), Transforming a university: The Scholarship of Teaching and Learning in practice (pp. 223-232). Sydney: Sydney University Press.

Postman, N., \& Weingartner, C. (1969). Teaching as a subversive activity. New York, NY: Dell Publishing.

Rhoades, G. (1998). Managed professionals: Unionized faculty and the restructuring of academic labor. Albany, NY: State University of New York Press.

Rice, R. E. (2006). From Athens to Berlin to LA: Faculty work and the new academy. Liberal Education, 92(4), 6-13.

Richlin, L., \& Cox, M. D. 2004. Developing scholarly teaching and the Scholarship of Teaching and Learning through faculty learning communities. New Directions for Teaching and Learning, 97, 127-135.

Roth, W-M., \& McGinn, M. K. (1997). Graphing: Cognitive ability or practice? Science Education, 81(1), 91-106.

Roxa, T., Olsson, T., \& Martensson, K. (2008). Appropriate use of theory in the Scholarship of Teaching and Learning as a strategy for institutional development. Arts and Humanities in Higher Education, 7(3), 276294.

Schneider, C. G. (2013). Did you know? Employers do not want narrow, illiberal learning! Liberal Education, 99(1), 2-3.

Shulman, L. S. (1993). Teaching as community property: Putting an end to pedagogical solitude. Change: The Magazine of Higher Learning, 25(6), 6-7.

Simmons, N., Abrahamson, E., Deshler, J., Kensington-Miller, B., Manarin, K., Moron-Garcia, Oliver, C. \& Renc-Roe, J. (2013.) Conflicts and configurations in a liminal space: SoTL scholars' identity development. Teaching \& Learning Inquiry, 1(2), 9-21.

Sommers, J. (2004). Two-year college English faculty and the Scholarship of Teaching and Learning: The journey awaits. Teaching English in the Two-Year College, 32(1), 14-25.

Voelker, D., \& Martin, R. (2013). Wisconsin teaching fellows \& scholars program assessment project: Final report. Retrieved from https://www.wisconsin.edu/opid/wisconsin-teaching-fellows-scholars-program/.

Weingarten, H. P. (2013, November 20). Managing for quality: A change manifesto for Canadian universities. [Web log comment]. Retrieved from http://blog-en.heqco.ca/2013/11/.

Wenger, E. (1998). Communities of practice: Learning, meaning, and identity. Cambridge: Cambridge University Press.

Werder, C., \& Otis, M. M. (Eds.). (2010). Engaging student voices in the study of teaching and learning. Sterling, VA: Stylus.

Wineburg, S. (2001). Historical thinking and other unnatural acts: Charting the future of teaching the past. Philadelphia, PA: Temple University Press. 
(c) (1)

Copyright for the content of articles published in Teaching \& Learning Inquiry resides with the authors, and copyright for the publication layout resides with the journal. These copyright holders have agreed that this article should be available on open access under a Creative Commons Attribution License 4.0 International (https://creativecommons.org/licenses/by/4.0). The only constraint on reproduction and distribution, and the only role for copyright in this domain, should be to give authors control over the integrity of their work and the right to be properly acknowledged and cited, and to cite Teaching \& Learning Inquiry as the original place of publication. Readers are free to share these materials - as long as appropriate credit is given, a link to the license is provided, and any changes are indicated. 